\title{
Strategies for Improving the Quality of Teacher Education in Local Undergraduate Normal University
}

\author{
Xiaodong Ding ${ }^{1, a}$ \\ ${ }^{1}$ College of Teacher Education, Qujing Normal University, Qujing, Yunnan, China \\ a1971161842@qq.com
}

Keywords: Teacher Education, Local Undergraduate Normal University, Quality, Strategy.

\begin{abstract}
With the popularization of higher education in China, a number of new local undergraduate normal universities are established. Therefore, teacher education has become the focus of these universities. However, the running foundation of these new established normal universities is relatively weak. Improving the quality of teacher education must be based on the regional educational ecology and focus on the strategies.
\end{abstract}

\section{Introduction}

With the popularization of higher education in China, a number of new local undergraduate universities have been established since 1999. The normal universities are also included, which have become an important part of higher education system. The local undergraduate universities in China are mainly responsible for training the local teachers of elementary education. Teacher education is the advantage and key field of local undergraduate normal universities. Improving the quality of teacher education is essential for these normal universities to cultivate more high-qualified and application-oriented teachers in local area. To solve the problem of how to improve the quality of teacher education, several strategies should be taken into consideration.

\section{To focus on the basic education issues and correct the education ideology}

Ideas generally determine solutions. The fundamental problem often lies in the ideology. While obtaining information, local undergraduate normal universities are relatively isolated. And their education ideology also needs to be updated. The education ideology lag has become the bondage of running a school. Updating the education ideology requires us to focus the fundamental education issues, that is, to explore the real education. Education is a true reflection of the reality of social life and culture. Some educational problems cannot be solved only by education itself. These problems are also restricted by social culture and traditional customs (ie., social life). Of course, this does not mean that we cannot obtain the real education. In fact, China is undergoing social transition. The backward or advanced ideas and social life co-exist, which requires us to stand at the forefront of the times because education cannot fall behind our life. Education should not only keep pace with our life. It should even be more advanced than it, leading the life. Although it is quite difficult for education to lead our life, it is our mission! Only the real education can lead our social life. However, in the tide of modern social life, a lot of education problems make education lost itself. We also unconsciously lost the direction of education. We should rethink a series of basic issues in education, for instance, "what is curriculum", "what is classroom and teaching", "who is the teacher", "who is the student", "what is education', etc. Perhaps it would be suddenly found that lots of mistakes in educational activities are due to the basic education issues, which are contrary to the true meaning of education. Therefore, we should update and correct our education ideology at the same time, especially the basic education issues. This guides us to update our education ideology and follow the law of education, which is the only way to improve the quality of teacher education. 


\section{To establish a scientific research and service platform under the guidance of the principle of regional educational ecology}

The education ecosystem is a unified system interacted by education and its surroundings. The sorts of internal education elements in this education ecosystem transmit and exchange the information, energy and matter, which shows the overall relevance. [1] The regional educational ecology is closely related to the survival and development of local universities, which is the special factor that influencing the development of these universities. The educational ecology is of regionality. Different regions consist of different educational ecology. Therefore, according to the overall principle of association, the principle of dynamic balance and the principle of co-evolution, etc., we should deal with the relationship between teacher education and its surroundings and reform the training method, structure and mode of teacher education in local universities in perspective of regional educational ecology. [2] Under the guidance of the above principle of regional educational ecology, three platforms are established as a whole, namely, "innovation research base of teacher education", "teaching team of teacher education" and "elementary education development center". "Innovation research base of teacher education" focuses on theoretical innovation. "Teaching team of teacher education" focuses on teaching and personnel training, which strengthens curriculum construction and teaching reform; "Elementary education development center" focuses on the social service for our society, primary school, secondary school and the family. Among them, "innovation research base of teacher education" needs the integration of local teacher education resources and the establishment of a regional experts database of teacher education. "Teaching team of teacher education" needs special attention on practical teaching. On one hand, local undergraduate normal universities should establish more infrastructures, which provides the students a fundamental condition for education skill training. On the other hand, based on the present educational practice base, "teacher development base" can be established, which is more important than infrastructures. "Teacher development base" can expand the functions of training base, which would be beneficial for the development of the teachers of this base, university teachers and the students of normal universities. These three platforms include personnel training, scientific research and social services and some other functions, as well as the theoretical and practical aspects. At work, we should have a global vision and adhere to the Chinese soul. More importantly, we should highlight the local features, which is based on local, reality and practice. Therefore, our education and scientific research would be more practical and make local undergraduate normal universities integrate into the regional educational ecology.

\section{To build up the thought of "scientific research first" in the construction of key subjects}

Subject construction is of great significance, which is the focus of university development. To strengthen teacher education, we must improve the construction of pedagogical subjects. Firstly, the team of qualified teachers is expected, which can be realized by introduction and training. The training includes overseas training, domestic key university training, campus job training and some other approaches. Secondly, the institutional and environmental issues need to be solved. Instead of busy with routine work, the teachers should have enough time to focus on academic research. From the point of view of teachers' team establishment, team members need to think about how we can work effectively in academic research. This requires that we should overcome all the difficulties. Thus we could output high level findings. From the perspective of system and environment, the leaders at all levels of a school and its management departments should think that what the influences of our management on academic research are. Only in this way, we could overcome the phenomenon of person-based, job-based and sector-based, which helps us to better services for subject construction. Among the solutions, giving way for subject construction is a very good type of service. Subject construction cannot be inseparable from scientific research. According to the weak scientific research of the local undergraduate normal universities, the thought of "scientific research first" in the construction of key subjects must be built up. The idea of "scientific research first" and the talent 
training are complementary. "Scientific research first" refers to research ideas first, researchers first, research time first, research funding first and research evaluation first, etc. That is, the scientific research should be the most prominent. In terms of funding, personnel, the scientific research should be a priority. The teachers should have more time for research and professional development. While evaluating the teachers' performance, the academic findings should be the focus, which would highlight the power of scientific research. This would also promote the teachers' gradual transformation from teaching to researching. Meanwhile, the innovation of grassroots academic organizations and the integration of experts on and off campus would guide the outstanding students engaged in scientific research and effectively organize high-level scientific research application. Through this policy-oriented strategy, we could constantly improve the level of the teachers' scientific research.

\section{To enhance the construction of core curriculums with the help of modern educational technology}

The core curriculums are the key to professional training, which directly determines the quality and structure of the personnel training. Therefore, we must persevere to strengthen the core curriculum construction. Two approaches can be included, developing the core curriculums by ourselves and introducing others' curriculums. With the development of educational informationization, the education reform and development are rapid. Large open online courses, namely MOOC (massive open online courses), demonstrates the prospect of high-quality curriculum resources, which has aroused our great attention. Open online courses represents the new generation of online education, which can be obtained through network and is of great benefit for the students. This phenomenon is "a digital tsunami", which is proposed by the president of Stanford University. He said this may wash away all the traditional university education. [3] Therefore, the teachers of local undergraduate normal universities should be organized to visit the research centers and other institutions related to MOOC, which helps to enhance their sense of crisis and promote the modernization of school education. More importantly, schools should strengthen curriculum construction, especially the core curriculum construction. Only continuously improve the teaching quality, could we keep up with the pace of modernization of higher education.

\section{To cultivate excellent teachers with an open horizon}

Training excellent teachers is the returning to "elite education" in the popularization of higher education, which would achieve the dialectical negation and development of Chinese higher education. In 2010, the Ministry of Education of People's Republic of China promoted to comprehensively reform education and education and started the implementation of "Excellent Teacher Education Project". The training objectives of this project to make the teachers obtain noble morality, professional knowledge, proficient skills and scholarly appearance, which makes them high-qualified and professional talents in local elementary education. After then, normal universities, including the new established local undergraduate normal universities, have tried to train excellent teachers. It is new for the local universities to train excellent teachers, which has been a supporting point for the development of a school and its teachers and students. Therefore, it is of great significance and can even push the improvement of the school system.

Excellent talents have the features of high comprehensive quality, great theoretical foundation, strong practice and innovation ability, fluent English and so on. They have a global vision, critical spirit and a strong sense of social responsibility. They are able to identify the problems immediately and solve them. Excellent teachers should own the same features of excellent talents with the essence of elite. Some researches show that the excellent teachers in elementary education depend on their teaching organization and management, professional knowledge, teaching reflection and research, which are also their key features and have become the essence of training objectives. [4] These teachers, as the elite in elementary education, are professional in education, teaching, management and research. The excellent teachers cultivated by local undergraduate normal universities should 
also have the feature of locality, which refers that they should master the local culture. In addition, according to the students' grades, the training objectives and the specific training contents should be different. Obviously, the training objectives of local undergraduate normal universities should be based on the features of teachers' occupation, the excellent talents' commonality, as well as the specialty of teachers in different grades and the locality, etc.

Reform is drove by opening up. Foreign advanced ideas and experiences play a vital role in solving some internal governance problems. Local undergraduate normal universities can adopt joint training mode and promote training reform, which aims to produce more advanced teaching philosophy, better teaching team and curriculum construction, and finally keeps pace with international ones. If the local undergraduate normal universities can cooperate with foreign universities to run a project of training excellent talents, it will greatly improve the openness of their project and the effectiveness of the project.

What should be noted is that there are some existed examples of training excellent teachers in China. To avoid unnecessary mistakes, we need to visit these universities to learn from their experience. This would help us avoid "losing our soul while pursuing excellence" (United States, Lewis). During the processing of training excellent teachers in elementary education, we need practice, research and innovation at the same time in all aspects. While facing the weak conditions of running a local normal university (e.g., the teachers, quality of students, etc.), we would suffer much difficulties in training excellent teachers in elementary education, which requires our big efforts.

\section{Using scientific evaluation criteria to monitor the teaching quality}

In the processing of teacher education reform promoted by Ministry of Education of the People's Republic of China, we should explore the training mode of teacher education and develop the practical teacher education criteria which are based on the professional criteria of teacher education and the curriculum criteria and assessment criteria proposed by Ministry of Education. Therefore, we could provide evidence for the teaching supervision and the quality evaluation of teacher education. These criteria should include curriculum settings, curriculum syllabus and examination syllabus, test database, etc. These elements are all fundamental and require large manpower for organization and implementation. In addition, "the separation of teaching and testing" is the basic principle of teaching supervision and evaluation. Thus, a variety of teaching supervision and evaluation methods are worked out. We should also develop scientific evaluation criteria of teaching quality according to the principle of "the separation of teaching and testing" which is for making objective teaching evaluation. This would effectively promote the teacher education reform and improve the teaching quality.

In conclusion, local undergraduate normal universities need to improve the quality of teacher education with a prerequisite of correcting and updating their education ideology, which is much tougher. Academic ability is the key factor, as well as a restriction on the development of the local undergraduate normal universities. Curriculum settings, teaching reform and supervision are all of great significance and need consistent concern. And what should be noted is the solution depends on the basic issue of local educational ecology and practical needs.

\section{References}

[1] Q. Gao. Problems and Countermeasures in Teachers' Professional Development -- Based on the Educational Ecology. Education Exploration, 2010 (11): 96-98.

[2] X.D. Ding. The Training of Children's Teachers in Perspective of Regional Ecological Education. SHI Hongjia \& LI Guojiang. The Innovation, Cooperation and Sustainability of Teacher Education -Corpus of 2013 Higher Symposium on Teacher Education, Qujing Normal University. Yunnan People's Publishing House, 2014: 143-150.

[3] What is MOOC? http://so.360.cn/s?ie=utf-8\&src=hao_search\&q=mooc\%E6\%98\%AF\%E4\% BB $\% 80 \%$ E4\% B9\% 88 
[4] Q. Li, D.D. Wu \& Y.L. Li. Key Features of Outstanding Teachers in Elementary and Secondary Schools: Findings Based on a Discriminant Analysis. Journal of Educational Studies, 2012 (8): 89-94. 